\title{
Analysis of renal functions and proteinuria in young obese adults
}

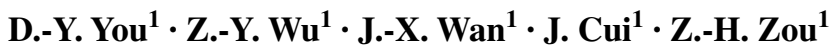

Received: 29 October 2014 / Accepted: 15 March 2015 / Published online: 2 April 2015

(C) The Author(s) 2015. This article is published with open access at Springerlink.com

\begin{abstract}
Objective To investigate the prevalence of obesity in young adults and to analyze the influencing factors on renal functions and proteinuria in this population.

Methods This study comprised civil servants between 20 and 39 years old, who received physical examinations at the First Affiliated Hospital of Fujian Medical University. The subjects were categorized into four groups based on age (20-24, 25-29, 30-34 and 35-39 years) and the number of risk factors they had (hypertension, dyslipidemia, hyperglycemia and hyperuricemia). The relationships between obesity and the prevalence of proteinuria, between obesity and risk factors and between estimated glomerular filtration rate (eGFR) and proteinuria were analyzed.

Results Among the 2293 young civil servants, in men the prevalence of obesity was $33.3 \%$ and proteinuria was $2.5 \%$. However in women the prevalence of obesity and proteinuria was $7.5 \%$ and $1.7 \%$, respectively. The levels of blood pressure, serum uric acid (UA), cholesterol (TC), triglyceride (TG), fasting glucose (FBG) and low-density lipoprotein cholesterol (LDL-C) were lower and the level of serum high-density lipoprotein cholesterol (HDL-C) was higher in nonobese groups compared with obese groups. There were no significant differences in eGFR between the two groups. The eGFR in male subjects was associated with age, UA, body mass index (BMI), FBG, TC, TG, LDL and HDL, and in female subjects associated with UA, age, BMI, diastolic blood pressure, FBG and LDL. BMI in both males and females increased with the higher number of risk
\end{abstract}

J.-X. Wan

wanjx@263.net

1 Department of Nephrology, The First Affiliated Hospital of Fujian Medical University, Fuzhou 350005, China factors. Multiple regression analysis revealed that hypertension, dyslipidemia, hyperglycemia and hyperuricemia were independently associated with obesity. eGFR decreased with a higher number of risk factors. Obesity, blood pressure, dyslipidemia, hyperglycemia and hyperuricemia were independently associated with proteinuria.

Conclusion Obesity can pose an independent risk factor for proteinuria in young adults. Hypertension, dyslipidemia, hyperglycemia and hyperuricemia were independently associated with obesity. eGFR decreased with a higher number of risk factors.

Keywords Obesity Young adults $\cdot$ Proteinuria . Renal function $\cdot$ Chronic kidney disease

\section{Introduction}

Obesity has become a global epidemic and its prevalence in adult population is increasing at a rapid pace. Obesity, along with hypertension, impaired glucose tolerance or diabetes mellitus and dyslipidemia are well-known factors of metabolic syndrome. Together, they increase the risk of cardiovascular disorders and chronic kidney disease (CKD). Currently, kidney damages attributed to obesity are getting more attention. The morbidity of obesity-related glomerulopathy (ORG) increases with obesity. In the USA, the morbidity of ORG was $0.2 \%$ in 1986-1990, while it increased to about $2 \%$ in 1996-2000 [1]. Therefore, it is crucial that renal damage in young obese adults should be analyzed at the early stage. The aim of this study was to compare the clinical characteristics of obese vs. nonobese young adult subjects and to analyze the factors that influence decreased renal function and proteinuria in young obese adults. 


\section{Subjects and methods}

\section{Study population}

The subjects were young civil servants between 20 and 39 years old in Fuzhou City. They received physical examination at the First Affiliated Hospital of Fujian Medical University between November 2008 and August 2009. Subjects who failed to provide data such as routine urine test and serum creatinine were excluded from the study. Also, of the subjects who received repeated examinations, only the first examination results were included.

\section{Measurements}

\section{Physical examination}

The height, body weight, body mass index (BMI), systolic blood pressure (SBP) and diastolic blood pressure (DBP) of all subjects were measured according to the unified standards. The BMI of each subject was calculated by dividing the weight $(\mathrm{kg})$ by the square of the height $\left(\mathrm{m}^{2}\right)$. The blood pressure was measured using an electrical manometer after letting the subjects rest for $15 \mathrm{~min}$. Blood pressure measurement was performed up to three times according to JNCVII standard, and the mean value was used for statistical analysis. The interval between each measurement was $5 \mathrm{~min}$. In case there was a difference of more than $10 \mathrm{mmHg}$ between two measurements; we chose the two closest measurements to calculate the mean value. The subject's height was defined as net height measured without shoes. Body weight was measured with empty stomach and no coat.

\section{Laboratory tests}

For laboratory analysis, subjects' morning urine samples were collected. Female subjects who were menstruating were excluded. Serum creatinine (Scr), urea nitrogen (BUN), uric acid (UA), fasting glucose (FBG), total cholesterol (TC), triglycerides (TG), high-density lipoprotein cholesterol (HDL-C) and low-density lipoprotein cholesterol (LDL-C) were tested. Urinary protein and occult blood were measured by urine dipstick test. Urine red cell counting was carried out by an automatic analyzer (uFl00, Sysmex, Japan). Proteinuria $\geq 0.3 \mathrm{~g} / \mathrm{L}$ was considered positive. FBG was detected by hexokinase method with an intra-assay coefficient of variation $<2.0 \%$ and inter-assay coefficient of variation $<2.5 \%$. FBG $\geq 6.1 \mathrm{mmol} / \mathrm{L}$ was considered abnormal. TC, TG, HDL-C, LDL-C, UA and Scr were measured using a full automatic biochemical analyzer (Hitachi 7600) with an intra-assay coefficient of variation $<1.5 \%$ and inter-assay coefficient of variation $<2.5 \%$.
Diagnostic code

Estimated glomerular filtration rate (eGFR) was calculated using the equation of MDRD as follows: $186 \times \mathrm{Scr}(\mathrm{mg} / \mathrm{dl})$ $\wedge(-1.154) \times$ age $^{\wedge}(-0.203)$, including a correction factor of 0.742 for women [2]. $1 \mu \mathrm{mol} \mathrm{Scr}=0.0113 \mathrm{mg} / \mathrm{dl}$.

The diagnosis of metabolic syndrome (Chinese Diabetes Society, 2004) (1) Overweight or obesity was defined as $\mathrm{BMI} \geq 25.0 \mathrm{~kg} / \mathrm{m}^{2}$. (2) Dyslipidemia was defined as $\mathrm{TG} \geq 1.70 \mathrm{mmol} / \mathrm{L}$ and/or HDL-C $<0.9 \mathrm{mmol} / \mathrm{L}$ (men) and $<1.0 \mathrm{mmol} / \mathrm{L}$ (women). (3) Hypertension was defined as $\mathrm{SBP} \geq 140 \mathrm{mmHg}$ and/or DBP $\geq 90 \mathrm{mmHg}$, including those who had been diagnosed with hypertension and had received treatment. (4) Hyperglycemia was defined as $\mathrm{FBG} \geq 6.1 \mathrm{mmol} / \mathrm{L}$ and $2 \mathrm{~h}$ postprandial blood glucose $\geq 11.1 \mathrm{mmol} / \mathrm{L}$, and/or those who had been diagnosed with diabetes. (5) Hyperuricemia was defined as UA $\geq 420 \mu \mathrm{mol} / \mathrm{L}$ (men) and $\geq 360 \mu \mathrm{mol} / \mathrm{L}$ (women). Based on the number of CKD risk factors (dyslipidemia, hypertension, hyperglycemia and hyperuricemia), the subjects were classified into group 0 (no risk factor), group 1 (one risk factor), group 2 (two risk factors) and group 3 (three or four risk factors).

\section{Statistical analysis}

All the data were entered into Excel by two researchers. The data were presented as $x \pm s$. Student's $t$ test was used to evaluate differences between the obese and nonobese groups. The enumeration data were analyzed by $\chi^{2}$ test. Related risk factors that affect renal function were analyzed by multivariate regression analysis and stepwise regression analysis with variables including age, BMI, SBP, DBP,

Table 1 Characteristics of males and females analyzed

\begin{tabular}{llll}
\hline Characteristics & Male & Female & $P$ value \\
\hline$n$ & 1292 & 1001 & - \\
Age (years) & $31.8 \pm 5.5$ & $31.3 \pm 5.3$ & 0.042 \\
Body mass index $\left(\mathrm{kg} / \mathrm{m}^{2}\right)$ & $23.5 \pm 3.3$ & $21.1 \pm 2.6$ & 0.000 \\
Obesity $(\%)$ & 33.3 & 7.5 & 0.000 \\
Systolic BP $(\mathrm{mm} \mathrm{Hg})$ & $114.3 \pm 13.4$ & $106.7 \pm 11.8$ & 0.000 \\
Diastolic BP $(\mathrm{mm} \mathrm{Hg})$ & $75.7 \pm 9.8$ & $69.9 \pm 8.7$ & 0.000 \\
Proteinuria $(\%)$ & 2.5 & 1.7 & 0.000 \\
Serum creatinine $(\mu \mathrm{mol} / \mathrm{L})$ & $75.2 \pm 9.8$ & $51.7 \pm 7.3$ & 0.000 \\
eGFR $(\mathrm{ml} / \mathrm{min})$ & $113.9 \pm 17.8$ & $131.2 \pm 21.7$ & 0.000 \\
FBG $(\mathrm{mmol} / \mathrm{L})$ & $5.0 \pm 0.7$ & $4.8 \pm 0.4$ & 0.000 \\
TC $(\mathrm{mmol} / \mathrm{L})$ & $4.88 \pm 0.91$ & $4.60 \pm 0.82$ & 0.000 \\
TG $(\mathrm{mmol} / \mathrm{L})$ & $1.54 \pm 1.03$ & $0.87 \pm 0.45$ & 0.000 \\
LDL-C $(\mathrm{mmol} / \mathrm{L})$ & $2.80 \pm 0.76$ & $2.44 \pm 0.68$ & 0.000 \\
HDL-C $(\mathrm{mmol} / \mathrm{L})$ & $1.32 \pm 0.28$ & $1.60 \pm 0.34$ & 0.000 \\
UA (mmol/L) & $383.6 \pm 69.3$ & $271.5 \pm 51.5$ & 0.000 \\
\hline
\end{tabular}


FBG, TC, TG, LDL-C, HDL-C and UA. Related risk factors for proteinuria were analyzed by two classifications of non-conditional logistic regression analysis with variables including gender, age, BMI, obesity, hypertension, dyslipidemia, high FBG and hyperuricemia. All data were analyzed using SPSS version 11.7.

\section{Results}

\section{Subjects' baseline characteristics and physical examination data}

A total of 1292 male and 1001 female eligible subjects were enrolled in our study. Their baseline characteristics are represented in Table $1.33 .3 \%$ of male and $7.5 \%$ of female subjects were obese. The gender differences in the characteristics of obesity and nonobesity in different age groups and in the same age group are shown in Tables 2 and 3. The average age was similar between obese and nonobese subjects in different age groups. In male subjects of different ages, blood pressure, TC, TG and LDL-C were higher, while HDL-C level was lower in the obese group compared with the nonobese group. UA in the 25- to 29-year age group, 30- to 34-year age group and 35- to 39-year age group was higher in the obese group than in the nonobese group. FBG in the 30- to 34-year age group and in the 35to 39-year age group was higher in the obese group than in the nonobese group. In female subjects, HDL-C in the 25- to 29-year age group, 30- to 34-year age group and 35to 39 -year age group was lower in the obese group than in the nonobese group. TG and UA in the 30- to 34-year age
Table 2 Characteristics of male obese and nonobese subjects

\begin{tabular}{|c|c|c|c|c|c|c|}
\hline \multirow[t]{2}{*}{ Characteristics } & \multicolumn{3}{|l|}{ 20-24 years } & \multicolumn{3}{|l|}{$25-29$ years } \\
\hline & Obese & Nonobese & $P$ value & Obese & Nonobese & $P$ value \\
\hline$N$ & 31 & 126 & - & 88 & 179 & - \\
\hline Age (years) & $22.6 \pm 1.3$ & $22.3 \pm 1.3$ & 0.160 & $27.1 \pm 1.5$ & $26.7 \pm 1.4$ & 0.488 \\
\hline Body mass index $\left(\mathrm{kg} / \mathrm{m}^{2}\right)$ & $27.1 \pm 2.4$ & $20.7 \pm 2.1$ & 0.000 & $27.2 \pm 2.3$ & $21.5 \pm 2.1$ & 0.000 \\
\hline Systolic BP (mm Hg) & $120.6 \pm 20.3$ & $114.3 \pm 13.4$ & 0.037 & $115.9 \pm 13.2$ & $114.3 \pm 12.1$ & 0.312 \\
\hline Diastolic BP (mm Hg) & $77.6 \pm 11.4$ & $72.8 \pm 8.3$ & 0.008 & $77.3 \pm 10.1$ & $73.3 \pm 8.8$ & 0.001 \\
\hline Proteinuria (\%) & 0 & 4.5 & 0.000 & 3.4 & 2.2 & 0.572 \\
\hline Serum creatinine $(\mu \mathrm{mol} / \mathrm{L})$ & $76.7 \pm 10.3$ & $75.0 \pm 8.3$ & 0.323 & $77.7 \pm 9.6$ & $75.7 \pm 9.0$ & 0.100 \\
\hline eGFR (ml/min) & $119.1 \pm 19.0$ & $121.9 \pm 16.2$ & 0.408 & $112.7 \pm 16.3$ & $116.1 \pm 17.0$ & 0.119 \\
\hline $\mathrm{FBG}(\mathrm{mmol} / \mathrm{L})$ & $5.1 \pm 0.7$ & $4.9 \pm 0.6$ & 0.206 & $4.9 \pm 0.6$ & $4.9 \pm 0.4$ & 0.686 \\
\hline $\mathrm{TC}(\mathrm{mmol} / \mathrm{L})$ & $4.73 \pm 0.70$ & $4.44 \pm 0.78$ & 0.053 & $5.34 \pm 0.93$ & $4.63 \pm 0.85$ & 0.000 \\
\hline $\mathrm{TG}(\mathrm{mmol} / \mathrm{L})$ & $1.33 \pm 0.68$ & $1.07 \pm 0.58$ & 0.038 & $2.11 \pm 1.35$ & $1.24 \pm 0.74$ & 0.000 \\
\hline $\mathrm{LDL}(\mathrm{mmol} / \mathrm{L})$ & $2.86 \pm 0.59$ & $2.52 \pm 0.66$ & 0.011 & $3.19 \pm 0.79$ & $2.57 \pm 0.73$ & 0.000 \\
\hline $\mathrm{HDL}(\mathrm{mmol} / \mathrm{L})$ & $1.19 \pm 0.17$ & $1.38 \pm 0.29$ & 0.002 & $1.25 \pm 0.25$ & $1.37 \pm 0.29$ & 0.001 \\
\hline $\mathrm{UA}(\mathrm{mmol} / \mathrm{L})$ & $402.7 \pm 79.3$ & $378.9 \pm 71.1$ & 0.105 & $409.2 \pm 71.6$ & $371.6 \pm 63.8$ & 0.000 \\
\hline \multirow[t]{2}{*}{ Characteristics } & \multicolumn{3}{|l|}{ 30-34 years } & \multicolumn{3}{|l|}{$35-39$ years } \\
\hline & Obese & Nonobese & $P$ value & Obese & Nonobese & $P$ value \\
\hline$N$ & 126 & 241 & - & 185 & 316 & - \\
\hline Age (years) & $32.3 \pm 1.4$ & $32.1 \pm 1.4$ & 0.264 & $37.1 \pm 1.4$ & $37.1 \pm 1.4$ & 0.856 \\
\hline Body mass index $\left(\mathrm{kg} / \mathrm{m}^{2}\right)$ & $27.1 \pm 2.8$ & $21.9 \pm 2.0$ & 0.000 & $27.0 \pm 1.6$ & $22.1 \pm 1.9$ & 0.000 \\
\hline Systolic BP (mm Hg) & $115.1 \pm 11.7$ & $112.0 \pm 12.0$ & 0.009 & $118.7 \pm 15.0$ & $112.1 \pm 13.1$ & 0.000 \\
\hline Diastolic BP (mmHg) & $78.3 \pm 9.7$ & $73.8 \pm 8.9$ & 0.000 & $81.6 \pm 11.3$ & $75.1 \pm 9.3$ & 0.000 \\
\hline Proteinuria (\%) & 4.8 & 1.2 & 0.068 & 4.3 & 0.6 & 0.007 \\
\hline Serum creatinine $(\mu \mathrm{mol} / \mathrm{L})$ & $75.9 \pm 11.1$ & $76.0 \pm 9.2$ & 0.831 & $75.3 \pm 10.4$ & $73.2 \pm 10.1$ & 0.035 \\
\hline eGFR (ml/min) & $112.7 \pm 19.0$ & $114.5 \pm 15.4$ & 0.515 & $110.3 \pm 17.8$ & $113.8 \pm 19.0$ & 0.039 \\
\hline $\mathrm{FBG}(\mathrm{mmol} / \mathrm{L})$ & $5.2 \pm 0.7$ & $4.9 \pm 0.5$ & 0.000 & $5.3 \pm 1.3$ & $5.0 \pm 0.7$ & 0.000 \\
\hline $\mathrm{TC}(\mathrm{mmol} / \mathrm{L})$ & $5.10 \pm 1.14$ & $4.82 \pm 0.85$ & 0.008 & $5.23 \pm 0.87$ & $4.82 \pm 0.82$ & 0.000 \\
\hline $\mathrm{TG}(\mathrm{mmol} / \mathrm{L})$ & $2.03 \pm 1.35$ & $1.33 \pm 0.94$ & 0.000 & $2.11 \pm 1.21$ & $1.41 \pm 0.77$ & 0.000 \\
\hline $\mathrm{LDL}(\mathrm{mmol} / \mathrm{L})$ & $2.97 \pm 0.92$ & $2.74 \pm 0.72$ & 0.010 & $3.07 \pm 0.74$ & $2.74 \pm 0.68$ & 0.000 \\
\hline $\mathrm{HDL}(\mathrm{mmol} / \mathrm{L})$ & $1.22 \pm 0.21$ & $1.35 \pm 0.27$ & 0.000 & $1.21 \pm 0.23$ & $1.36 \pm 0.30$ & 0.000 \\
\hline $\mathrm{UA}(\mathrm{mmol} / \mathrm{L})$ & $402.6 \pm 71.0$ & $373.8 \pm 66.4$ & 0.000 & $395.9 \pm 69.7$ & $376.1 \pm 67.3$ & 0.009 \\
\hline
\end{tabular}


Table 3 Characteristics of female obese and nonobese subjects

\begin{tabular}{|c|c|c|c|c|c|c|}
\hline \multirow[t]{2}{*}{ Characteristics } & \multicolumn{3}{|l|}{ 20-24 years } & \multicolumn{3}{|l|}{$25-29$ years } \\
\hline & Obese & Nonobese & $P$ value & Obese & Nonobese & $P$ value \\
\hline$N$ & 4 & 118 & - & 12 & 242 & - \\
\hline Age (years) & $22.3 \pm 1.7$ & $22.6 \pm 1.3$ & 0.648 & $27.3 \pm 1.4$ & $26.8 \pm 1.4$ & 0.198 \\
\hline Body mass index $\left(\mathrm{kg} / \mathrm{m}^{2}\right)$ & $27.8 \pm 2.0$ & $19.6 \pm 1.9$ & 0.000 & $26.0 \pm 0.9$ & $20.3 \pm 2.0$ & 0.000 \\
\hline Systolic BP (mm Hg) & $108.3 \pm 3.6$ & $107.5 \pm 11.2$ & 0.895 & $111.2 \pm 10.1$ & $106.1 \pm 10.7$ & 0.106 \\
\hline Diastolic BP (mmHg) & $70.3 \pm 4.6$ & $63.9 \pm 7.4$ & 0.724 & $71.5 \pm 8.7$ & $65.0 \pm 7.8$ & 0.290 \\
\hline Proteinuria (\%) & 0 & 1.6 & 0.000 & 8.3 & 1.2 & 0.136 \\
\hline Serum creatinine $(\mu \mathrm{mol} / \mathrm{L})$ & $53.0 \pm 7.0$ & $52.7 \pm 6.6$ & 0.929 & $51.4 \pm 6.5$ & $52.4 \pm 7.1$ & 0.629 \\
\hline eGFR (ml/min) & $134.9 \pm 16.8$ & $136.2 \pm 20.0$ & 0.898 & $134.5 \pm 19.8$ & $132.6 \pm 20.8$ & 0.754 \\
\hline $\mathrm{FBG}(\mathrm{mmol} / \mathrm{L})$ & $5.1 \pm 0.2$ & $4.7 \pm 0.4$ & 0.034 & $5.0 \pm 0.3$ & $4.7 \pm 0.4$ & 0.043 \\
\hline $\mathrm{TC}(\mathrm{mmol} / \mathrm{L})$ & $4.92 \pm 0.97$ & $4.43 \pm 0.69$ & 0.167 & $4.29 \pm 0.86$ & $4.56 \pm 0.87$ & 0.289 \\
\hline $\mathrm{TG}(\mathrm{mmol} / \mathrm{L})$ & $1.26 \pm 1.07$ & $0.77 \pm 0.30$ & 0.005 & $1.00 \pm 0.36$ & $0.83 \pm 0.51$ & 0.283 \\
\hline LDL (mmol/L) & $2.89 \pm 0.84$ & $2.30 \pm 0.51$ & 0.029 & $2.41 \pm 0.75$ & $2.39 \pm 0.74$ & 0.930 \\
\hline $\mathrm{HDL}(\mathrm{mmol} / \mathrm{L})$ & $1.35 \pm 0.29$ & $1.63 \pm 0.34$ & 0.114 & $1.33 \pm 0.29$ & $1.59 \pm 0.32$ & 0.008 \\
\hline $\mathrm{UA}(\mathrm{mmol} / \mathrm{L})$ & $310.5 \pm 36.0$ & $287.2 \pm 45.0$ & 0.309 & $299.6 \pm 48.9$ & $277.5 \pm 50.8$ & 0.255 \\
\hline \multirow[t]{2}{*}{ Characteristics } & \multicolumn{3}{|l|}{$30-34$ years } & \multicolumn{3}{|l|}{$35-39$ years } \\
\hline & Obese & Nonobese & $P$ value & Obese & Nonobese & $P$ value \\
\hline$N$ & 16 & 254 & - & 43 & 312 & - \\
\hline Age (years) & $32.3 \pm 1.2$ & $32.2 \pm 1.3$ & 0.698 & $37.0 \pm 1.5$ & $37.0 \pm 1.4$ & 0.973 \\
\hline Body mass index $\left(\mathrm{kg} / \mathrm{m}^{2}\right)$ & $27.5 \pm 2.1$ & $20.6 \pm 1.9$ & 0.000 & $26.9 \pm 2.0$ & $21.8 \pm 2.5$ & 0.000 \\
\hline Systolic BP (mm Hg) & $118.4 \pm 19.0$ & $105.8 \pm 11.6$ & 0.000 & $109.8 \pm 12.5$ & $106.6 \pm 12.4$ & 0.107 \\
\hline Diastolic BP (mmHg) & $80.3 \pm 11.3$ & $69.5 \pm 9.3$ & 0.000 & $74.0 \pm 9.9$ & $70.4 \pm 8.6$ & 0.064 \\
\hline Proteinuria (\%) & 6.3 & 2.0 & 0.309 & 2.3 & 1.2 & 0.515 \\
\hline Serum creatinine $(\mu \mathrm{mol} / \mathrm{L})$ & $50.1 \pm 6.5$ & $50.3 \pm 7.1$ & 0.889 & $51.6 \pm 7.6$ & $51.8 \pm 7.7$ & 0.904 \\
\hline eGFR (ml/min) & $134.3 \pm 20.6$ & $134.2 \pm 22.3$ & 0.994 & $127.0 \pm 21.8$ & $126.4 \pm 21.9$ & 0.931 \\
\hline FBG (mmol/L) & $5.0 \pm 0.5$ & $4.8 \pm 0.4$ & 0.159 & $4.9 \pm 0.5$ & $4.9 \pm 0.4$ & 0.724 \\
\hline $\mathrm{TC}(\mathrm{mmol} / \mathrm{L})$ & $5.34 \pm 1.44$ & $4.56 \pm 0.81$ & 0.000 & $4.86 \pm 0.82$ & $4.70 \pm 0.77$ & 0.191 \\
\hline $\mathrm{TG}(\mathrm{mmol} / \mathrm{L})$ & $1.45 \pm 0.63$ & $0.84 \pm 0.34$ & 0.000 & $1.23 \pm 0.63$ & $0.93 \pm 0.45$ & 0.000 \\
\hline LDL (mmol/L) & $3.26 \pm 1.38$ & $2.38 \pm 0.65$ & 0.000 & $2.70 \pm 0.76$ & $2.51 \pm 0.62$ & 0.083 \\
\hline $\mathrm{HDL}(\mathrm{mmol} / \mathrm{L})$ & $1.42 \pm 0.33$ & $1.60 \pm 0.34$ & 0.029 & $1.45 \pm 0.26$ & $1.61 \pm 0.35$ & 0.003 \\
\hline $\mathrm{UA}(\mathrm{mmol} / \mathrm{L})$ & $309.6 \pm 48.1$ & $260.8 \pm 49.6$ & 0.000 & $299.3 \pm 51.1$ & $265.7 \pm 53.0$ & 0.000 \\
\hline
\end{tabular}

group and in the 35- to 39-year age group was higher in the obese group than in the nonobese group. eGFR was similar in male and female subjects of different age groups.

\section{Risk factors of CKD}

We evaluated the relationships between CKD risk factors and BMI, and between the risk factors and eGFR. The percentage of group $0,1,2$ and 3 in male subjects was $41.6 \%$ $(n=538), 37.2 \%(n=481), 16.9 \%(n=218)$, and $4.3 \%$ $(n=55)$. The corresponding percentage in female subjects was $82.6 \%(n=826), 15.4 \%(n=154), 1.7 \%(n=17)$ and $0.4 \%(n=4)$. The mean ages of the four groups in male subjects were $31.4 \pm 5.4,31.7 \pm 5.4,32.8 \pm 5.0$ and $33.7 \pm 4.7$, respectively. The mean ages of the four groups in female subjects were $31.2 \pm 5.3,32.0 \pm 5.2$,
$33.2 \pm 4.7$ and $36.5 \pm 3.3$, respectively. There was no significant age difference in male and female subjects among all four groups $(P>0.05)$. The mean BMIs of the four groups in male subjects were $22.2 \pm 3.0,23.7 \pm 3.1$, $25.3 \pm 2.9$ and $26.7 \pm 3.0$, respectively. In female subjects, the mean BMIs were $20.8 \pm 2.4,22.2 \pm 3.0,23.1 \pm 2.7$ and $27.7 \pm 3.4$, respectively. BMI increased as the number of risk factors increased (Fig. 1). Multivariate analysis indicated that these risk factors were independently associated with obesity, as shown in Table 4. The eGFRs in the four groups were $115.1 \pm 17.5,113.4 \pm 17.6,113.1 \pm 17.7$ and $111.0 \pm 21.2 \mathrm{ml} / \mathrm{min}$ in male subjects, and $131.1 \pm 21.2$, $133.3 \pm 24.5,126.3 \pm 17.4$ and $116.2 \pm 17.0 \mathrm{ml} / \mathrm{min}$ in female subjects, respectively. There was no significant difference within group $(P>0.05)$. However, eGFR decreased as the number of risk factors increased (Fig. 2). 


\section{Multivariate analysis of eGFR}

Multivariate analysis showed that in both male and female subjects, eGFR was negatively correlated with age, BMI, UA and TC, positively correlated with FBG, HDL-C, LDL-C and TG, and not correlated with SBP (Table 5). The male and female eGFRs were considered as dependent variables and the age, BMI, DBP, FBG, HDL-C, LDL-C, TC, TG and UA were considered as independent variables in multiple regression analysis. The analysis indicated that in the male group, eGFR was correlated with age, UA, BMI, FBG, TC, TG, LDL-C and HDL-C. In the female group, eGFR was correlated with UA, age, BMI, DBP, FBG and LDL-C (Tables 6, 7).

\section{Proteinuria}

The prevalence of proteinuria in male and female subjects was 2.5 and $1.7 \%$, respectively, with no significant difference between two groups. The univariate odds ratios for
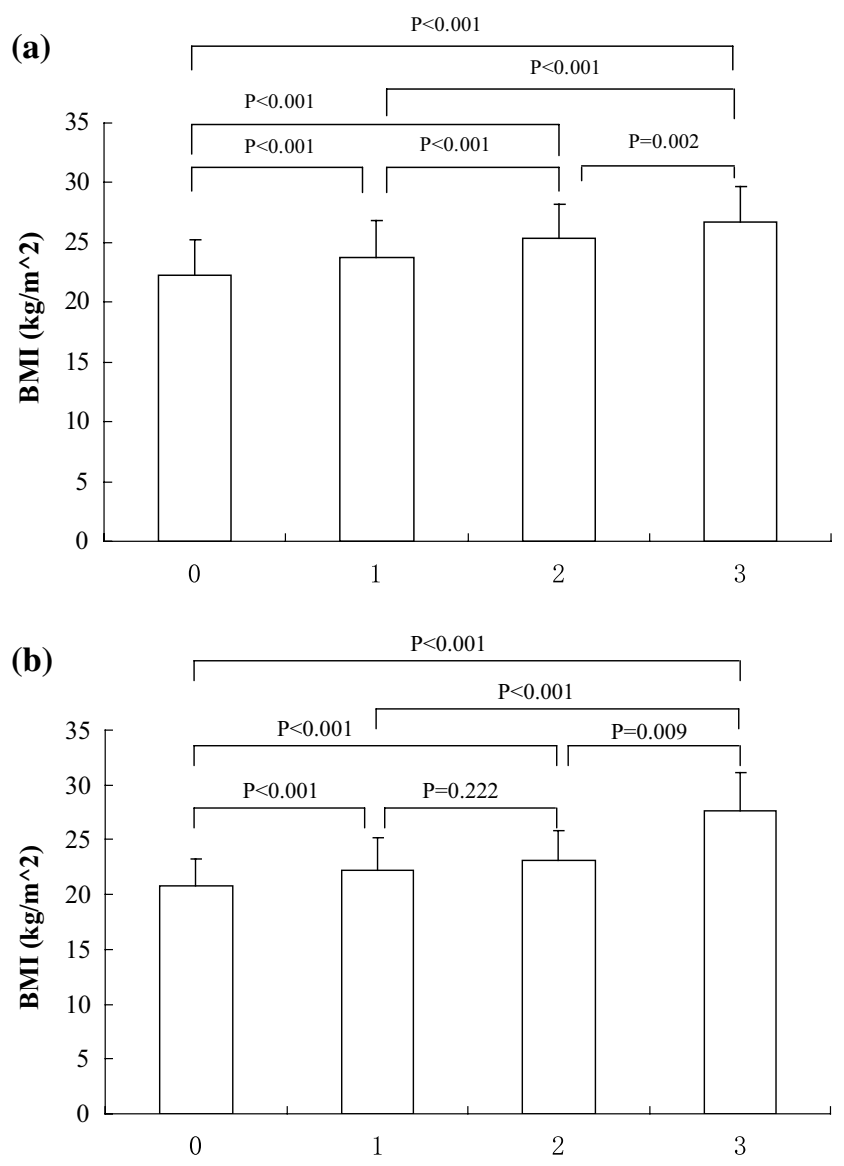

Fig. 1 a Relationship between male BMI and the number of risk factors. b Relationship between female BMI and the number of risk factors proteinuria of potential risk factors such as BMI, obesity, hypertension, dyslipidemia, high FBG and hyperuricemia are shown in Table 8 . The multivariate odds ratios for proteinuria of potential risk factors such as obesity, hypertension, dyslipidemia, high FBG and hyperuricemia are shown in Table 9. Univariate analysis and multivariate analysis showed that obesity, hypertension, dyslipidemia, high FBG and hyperuricemia were independently correlated with proteinuria. Hyperglycemia possesses the highest odds ratios for proteinuria. Conversely, increasing age was independently correlated with lower risk of proteinuria.

Table 4 Odds ratios of the risk factors and obesity

\begin{tabular}{lllr}
\hline & Odds ratio & $95 \%$ CI & $P$ value \\
\hline Gender & 0.298 & $0.225-0.395$ & $<0.001$ \\
Age & 1.039 & $1.017-1.062$ & 0.001 \\
High BP & 2.200 & $1.694-2.857$ & $<0.001$ \\
Hyperglycemia & 2.457 & $1.300-4.644$ & 0.006 \\
Hyperuricemia & 1.901 & $1.467-2.465$ & $<0.001$ \\
Dyslipidemia & 3.410 & $2.675-4.347$ & $<0.001$ \\
\hline
\end{tabular}
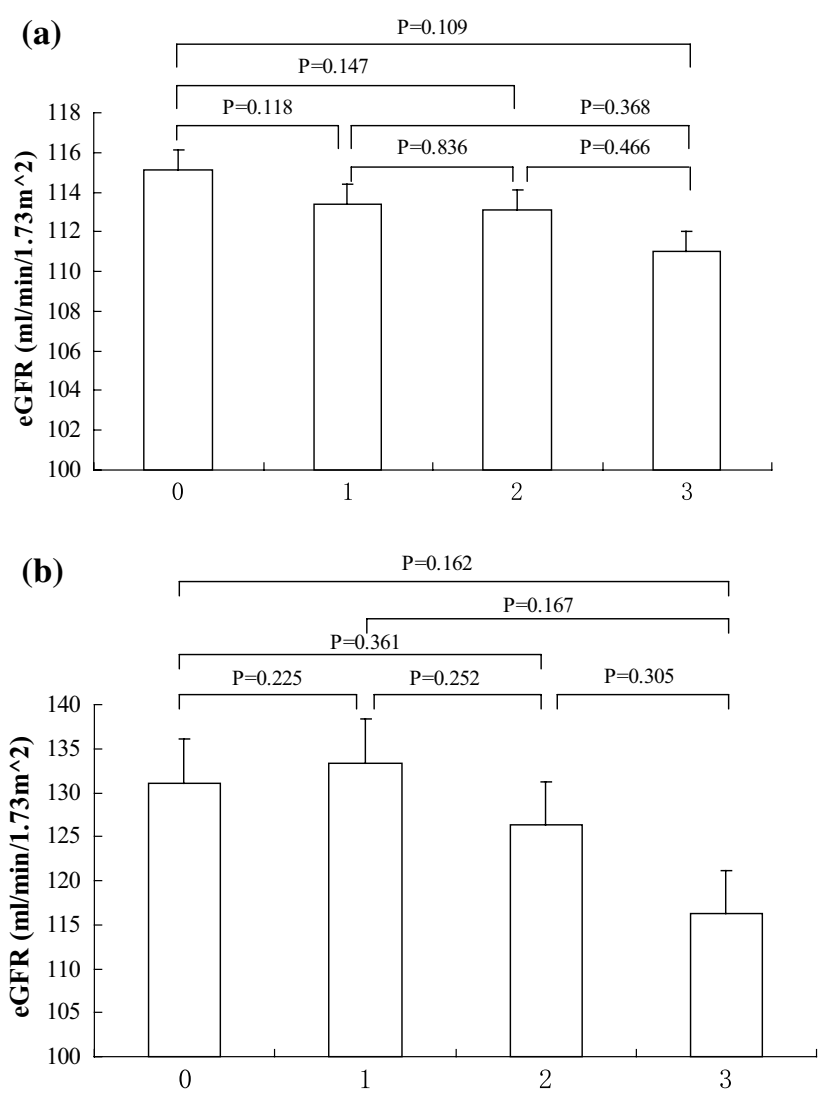

Fig. 2 a Relationship between male eGFR and the number of risk factors. b Relationship between female eGFR and the number of risk factors 
Table 5 Correlation analysis of male and female eGFR and related variables

\begin{tabular}{|c|c|c|c|c|c|c|c|c|c|c|}
\hline Group & Age & BMI & SBP & DBP & FBG & HDL & LDL & $\mathrm{TC}$ & TG & UA \\
\hline \multicolumn{11}{|l|}{ Male } \\
\hline$r$ value & -0.147 & -0.070 & 0.048 & -0.051 & 0.091 & 0.058 & 0.082 & -0.100 & 0.095 & -0.124 \\
\hline$P$ value & $<0.001$ & 0.012 & 0.089 & 0.066 & 0.001 & 0.039 & 0.003 & $<0.001$ & 0.001 & $<0.001$ \\
\hline \multicolumn{11}{|l|}{ Female } \\
\hline$r$ value & -0.145 & -0.040 & 0.016 & -0.055 & 0.057 & 0.080 & 0.051 & -0.071 & 0.075 & -0.298 \\
\hline$P$ value & $<0.001$ & 0.049 & 0.457 & 0.009 & 0.006 & $<0.001$ & 0.014 & 0.001 & $<0.001$ & $<0.001$ \\
\hline
\end{tabular}

Table 6 Multiple regression analysis of male eGFR and variables

\begin{tabular}{lllrr}
\hline Variable & Partial regression coefficient & Standard error of mean & Standard partial regression coefficient & $t$ value \\
\hline Age & -0.441 & 0.092 & -0.132 & -4.778 \\
UA & -0.033 & 0.007 & -0.128 & $<0.001$ \\
BMI & -0.487 & 0.175 & -0.090 & -4.514 \\
FBG & 2.340 & 0.679 & 0.095 & -2.790 \\
TC & -7.014 & 1.875 & -0.395 & 0.005 \\
TG & 2.566 & 0.739 & 0.150 & 0.001 \\
LDL-C & 5.902 & 1.947 & 0.252 & $<0.001$ \\
HDL & 5.833 & 2.754 & 0.092 & 0.001 \\
\hline
\end{tabular}

Table 7 Multiple regression analysis of female eGFR and variables

\begin{tabular}{lllrr}
\hline Variable & Partial regression coefficient & Standard error of mean & Standard partial regression coefficient & $t$ value \\
\hline Age & -0.560 & 0.079 & -0.139 & -7.073 \\
UA & -0.084 & 0.005 & -0.329 & $<0.001$ \\
BMI & -0.345 & 0.152 & -0.052 & $<0.001$ \\
DBP & -0.121 & 0.046 & -0.055 & -2.568 \\
FBG & 1.854 & 0.683 & 0.054 & -272 \\
LDL-C & -1.170 & 0.592 & -0.041 & 0.023 \\
\hline
\end{tabular}

Table 8 Univariate odds ratios of the risk factors for proteinuria

\begin{tabular}{lllr}
\hline Risk factor & Odds ratio & $95 \%$ CI & $P$ value \\
\hline Gender & 0.277 & $0.122-0.631$ & 0.002 \\
Age & 0.977 & $0.922-1.036$ & 0.442 \\
BMI & 1.120 & $1.034-1.214$ & 0.006 \\
Obesity & 2.789 & $1.470-5.294$ & 0.002 \\
High BP & 2.256 & $1.133-4.494$ & 0.021 \\
Hyperglycemia & 13.591 & $5.897-31.327$ & $<0.001$ \\
Hyperuricemia & 3.751 & $1.973-7.131$ & $<0.001$ \\
Dyslipidemia & 2.781 & $1.457-5.308$ & 0.002 \\
\hline
\end{tabular}

\section{Discussion}

In 2002, a survey conducted by China National Nutrition and Health showed that Chinese adults' overweight rate was $22.8 \%$. In our study population, the obesity rate of males between 20 and 39 years old was $33.3 \%$ and of females $7.5 \%$ with an average of $22.0 \%$ which was comparable to the previous finding. Blood pressure, serum uric acid, serum lipids and fasting glucose of obese subjects were higher than those of nonobese subjects. HDL-C of obese subjects was lower than that of nonobese subjects. It indicated that obese young adults had higher risk for developing hypertension, hyperlipidemia, hyperglycemia and hyperuricemia than nonobese counterparts. Hypertension, hyperlipidemia, hyperglycemia and hyperuricemia are the risk factors for CKD. Hypertension has been shown to be a significant risk factor for kidney failure in several large population-based studies [3-5]. Several cohort studies in the USA [6, 7] and Japan [8] have identified hyperlipidemia as also a possible risk factor for the development and progression of CKD. Diabetes has been considered as an initiation risk factor of CKD [9]. Cain et al. [10] found that increasing serum uric acid levels were positively associated 
Table 9 Multivariate odds ratios of the risk factors for proteinuria

\begin{tabular}{lclr}
\hline Risk factor & Odds ratio & $95 \%$ CI & $P$ value \\
\hline Gender & 0.544 & $0.215-1.375$ & 0.198 \\
Age & 0.952 & $0.895-1.012$ & 0.114 \\
BMI & 0.945 & $0.799-1.117$ & 0.506 \\
Obesity & 1.693 & $0.545-5.259$ & 0.033 \\
High BP & 1.348 & $0.632-2.874$ & 0.040 \\
Hyperglycemia & 10.926 & $4.413-27.050$ & $<0.001$ \\
Hyperuricemia & 2.751 & $1.363-5.550$ & 0.005 \\
Dyslipidemia & 1.713 & $0.802-3.658$ & 0.034 \\
\hline
\end{tabular}

with CKD. This association appeared to be independent of age, gender, smoking status, alcohol intake, education, diabetes mellitus, hypertension, BMI and total cholesterol levels. Our study also identified that eGFR decreased as the number of the above risk factors increased.

Obesity may be associated with increased risk for CKD independent of diabetes and hypertension [11]. For example, higher level of proteinuria is a risk factor of CKD [9]. Several studies had indicated that obesity was associated with proteinuria. Chagnac et al. [12] found that nondiabetic obese patients with normal blood pressure had higher albumin excretion rate, higher GFR and glomerular transmembrane pressure than normal people. The rise of glomerular transmembrane pressure will lead to the rise of GRF. The rise of GFR will cause the damage of glomerular filtration membrane and result in the rise of albumin excretion [13]. Tran et al. [14] reported a case of a 48-yearold male patient with severe obesity. When the patient's weight reduced to 118,110 and $102 \mathrm{~kg}$, respectively, his 24-h urinary protein excretion reduced to 7.6, 2.1 and $0.85 \mathrm{~g}$, respectively. The CARDIA study [15] showed that an unhealthy lifestyle (unhealthy diet, smoking and obesity) may lead to incident microalbuminuria. But there are few studies on the relationship between obesity and proteinuria in youth. In China, such study has not been performed previously. Our study showed that obesity was an independent risk factor for proteinuria in youth.

There were some limitations associated with our study. First, the subjects might have physiological proteinuria, but they had no fever and had been told not to do strenuous exercise before the test, which could decrease the falsepositive rate. Second, we did not test microalbuminuria. So, the morbidity of proteinuria might be underestimated in our study. Third, the diagnosis of obesity was based on the standard of Chinese Diabetes Society. We did not measure waists and hips. Thus, visceral obesity might be missed, which could also decrease the false-positive rate. Fourth, we used the equation of MDRD to estimate the glomerular filtration rate (eGFR). The MDRD equation was first proposed by the National Kidney Foundation, K/DOQI clinical practice guidelines for chronic kidney disease: evaluation, classification, and stratification in 2002 [2]. The MDRD equation is now widely used in nephrology. But this equation has some limitations. For example, creatinine is affected by the muscle mass of the subject. So if the subject is too fat or too thin, this equation is not accurate enough to estimate the GFR. Serum cystatin $C$ has been proposed as a simple, accurate and rapid endogenous marker of GFR in research and clinical practice. It is more stable than creatinine and less influenced by the muscle and gender. One meta-analysis showed that serum cystatin $\mathrm{C}$ was clearly superior to serum creatinine as a marker of GFR [16]. So in our further study, we may ues cystatin C to estimate GFR.

Conflict of interest All authors have no conflict of interest to disclose.

Ethical approval Our study had been approved by the Medical Ethics Committee of the First Affiliated Hospital of Fujian Medical University.

Informed consent Informed consent was obtained from all individual participants included in the study.

Open Access This article is distributed under the terms of the Creative Commons Attribution License which permits any use, distribution, and reproduction in any medium, provided the original author(s) and the source are credited.

\section{References}

1. Kambham N, Markowi GS, VaIeri AM et al (2001) Obesityrelated glomerulopathy: an emerging epidemic. Kidney Int 59(4):1498-1509

2. National Kidney Foundation (2002) K/DOQI clinical practice guidelines for chronic kidney disease: evaluation, classification, and stratification. Am J Kidney Dis 39(2 Suppl 1):S1-266

3. Klag MJ, Whelton PK, Randall BL et al (1996) Blood pressure and end-stage renal disease in men. N Engl J Med 334(1):13-18

4. Tozawa M, Iseki K, Iseki C et al (2003) Blood pressure predicts risk of developing end stage renal disease in men and women. Hypertension 41(6):1341-1345

5. O'Seaghdha CM, Perkovic V, Lam TH et al (2009) Blood pressure is a major risk factor for renal death: an analysis of 560352 participants from the Asia-Pacific region. Hypertension 54(3):509-515

6. Muntner P, Coresh J, Smith JC et al (2000) Plasma lipids and risk of developing renal dysfunction: the atherosclerosis risk in communities study. Kidney Int 58(1):293-301

7. Fox CS, Muntner P (2008) Trends in diabetes, high cholesterol, and hypertension in chronic kidney disease among US adults: 1988-1994 to 1999-2004. Diabetes Care 31(7):1337-1342

8. Iseki K, Yamazato M, Tozawa M et al (2002) Hypocholesterolemia is a significant predictor of death in a cohort of chronic hemodialysis patients. Kidney Int 61(5):1887-1893

9. Levey AS, Coresh J, Balk E et al (2003) National kidney foundation practice guidelines for chronic kidney disease: evaluation, classification, and stratification. Ann Intern Med 139(2):137-147 
10. Cain L, Shankar A, Ducatman AM et al (2010) The relationship between serum uric acid and chronic kidney disease among Appalachian adults. Nephrol Dial Transpl 25(11):3593-3599

11. Ejerblad E, Fored CM, Lindblad P et al (2006) Obesity and risk for chronic renal failure. J Am Soc Nephrol 17(6):1695-1702

12. Chagnac A, Weinstein T, Korzets A et al (2000) Glomerular hemodynamics in severe obesity. Am J Physiol Renal Physiol 278(5):817-822

13. Chagnac A, Weinstein T, Herman M et al (2003) The effects of weight loss on renal function in patients with severe obesity. J Am Soc Nephrol 14(6):1480-1486
14. Tran HA (2006) Reversible obesity-related glomerulopathy following weight reduction. Med J Aust 184(7):367

15. Chang A, Van Horn L, Jacobs DR Jr et al (2013) Lifestyle-related factors, obesity, and incident microalbuminuria: the CARDIA (Coronary Artery Risk Development in Young Adults) study. Am J Kidney Dis 62(2):267-275

16. Dharnidharka VR, Kwon C, Stevens G (2002) Serum cystatin C is superior to serum creatinine as a marker of kidney function: a meta-analysis. Am J Kidney Dis 40(2):221-226 